\title{
EL COMERCIANTE INGLÉS Y EL FABRICANTE DE PAÑOS: DE LA TRADUCCIÓN A LA ADAPTACIÓN
}

\author{
María Jesús GARCÍA GARROSA \\ Universidad de Valladolid
}

De los dos catálogos sobre traducciones españolas de obras teatrales francesas publicados por Francisco Lafarga ${ }^{1}$, se desprende que, en el período comprendido entre 1700 y 1835 , más de setecientos títulos franceses diferentes fueron adaptados en español, impresos o manuscritos, algunos de ellos con varias versiones. A ellos hay que añadir otra lista, menos numerosa, de títulos italianos y, en menor medida, ingleses y alemanes.

Lo elevado de estas cifras confirma, de entrada, la influencia nada desdeñable del teatro francés en los escenarios españoles durante el siglo XVIII y un tercio del XIX. Que la escena española se nutrió en buena medida de obras venidas de fuera queda, pues, más que probado, sin necesidad de extenderse en explicaciones. Pero me parece importante destacar que no siempre se ha prestado la debida atención al fenómeno en sí ni al proceso que dicho fenómeno implica. Es de suponer, por ejemplo, que en tan largo período las razones para acudir a las fuentes extranjeras debieron de ser diferentes, o que no todas esas traducciones se realizaron con los mismos criterio estéticos. Es éste precisamente el aspecto que ahora me interesa. ¿Cómo se realizaron esas traducciones?

Son de sobra conocidas las duras críticas de los ilustrados a los Valladares, Comellas y Arellano que inundaron los teatros españoles durante los últimos años del siglo XVIII de "traducciones que necesitaban traducción". ¿Hemos de suponer que las versiones de Moratín, Iriarte u Olavide tienen cualidades de las que aquéllos carecen? ¿La condena de ciertas traduccio-

1. Lafarga, F.: Las traducciones españolas del teatro francés (1700-1835). I: Bibliografía de Impresos, Universidad de Barcelona, 1983, y II: Catálogo de Manuscritos, Universidad de Barcelona, 1988. 
nes se basa únicamente en criterios lingüísticos y estilísticos?

La respuesta a ésta y otras preguntas que el tema sugiere necesitaría de un largo estudio, cuyo primer paso es el análisis particular y detallado del mayor número posible de esas traducciones y de sus originales. Las líneas que siguen son una aproximación a ese análisis.

Una buena parte de las traducciones realizadas en las tres décadas que van de 1700 a 1810 corresponden a obras del llamado género sentimental, tan famoso en Francia como en España, y del que salieron títulos que figuran entre los grandes éxitos, como Misantropía y arrepentimiento o El Abate de l'Épée.

El proceso de traducción de las obras de este género puede dividirse en tres etapas, que expongo sucintamente: una primera época ${ }^{2}$ centrada en torno a 1768 y a la que corresponden en su mayoría las traducciones realizadas como consecuencia de la Reforma de Aranda; una segunda etapa, que va de los años ochenta a 1799, en la que se incluyen las versiones de los grandes especialistas del género (Valladares, Enciso, etc.); y, por fín, la tercera y última, iniciada con la constitución de la Junta de Reforma de los Teatros, en la que se encuentran muchas obras alemanas traducidas a partir de versiones francesas ${ }^{3}$.

La etapa más fecunda e interesante es, sin duda, la segunda, no sólo porque en esos años (y gracias en buena medida a esas obras traducidas) el género sentimental se afianzó en los escenarios españoles, sino también porque la labor de traducción reviste características muy especiales que la diferencian de la de otros períodos.

Entre los más prolíficos traductores de finales del siglo se encuentra don Antonio Valladares de Sotomayor, autor de, al menos, dieciséis versiones españolas de obras francesas ${ }^{4}$ y tres de piezas italianas ${ }^{5}$.

En septiembre de 1784 se estrenó en Madrid su comedia El fabricante de paños o comerciante inglés (impresa sin lugar, ni fecha, ni nombre de editor), segunda versión española de la pieza de Fenouillot de Falbaire Le fabricant de Londres ${ }^{6}$. En efecto, en el año 1778 se representó en Barcelona ${ }^{7}$ una obra

2. Excluyo, por su fecha temprana y su carácter de obra pionera sin continuaciones inmediatas, la primera traducción, La razón contra la moda, realizada por Luzán en 1751.

3. Las características de cada una de estas etapas están descritas en García Garrosa, M. J.: La retórica de las lágrimas (La comedia sentimental española: 1751-1802), en prensa, y, del mismo autor: "Recepción del teatro sentimental en España", Actas del Coloquio Imágenes de Francia en las Letras Hispánicas (Barcelona, Nov. 1988).

4. Cf. Lafarga, ops. cits.

5. Cf. McClelland, I. L.: Spanish Drama of Pathos, 1750-108, Liverpool, 1970, 2 vols.

6. La obra de Fenouillot de Falbaire (1771) es, a su vez, la segunda versión en francés del original inglés de Lillo: The London Merchant (1731); la primera versión fue realizada en 1748 por Clément de Genève.

7. Cf. Par, A.: "Representaciones teatrales en Barcelona durante el siglo XVIIl", Boletín de la Real Academia Española, XVI (1929), pp. 326-346, 492-513, 594-614. 
titulada El comerciante de Londres, título que sin duda corresponde a la comedia El comerciante inglés, impresa sin fecha, en Barcelona, y de autor desconocido ${ }^{8}$.

Tenemos, pues, dos versiones de un mismo original francés separadas por un lapso de tiempo de al menos seis años y muy diferentes entre sí.

Ignoramos la razón por la que el anónimo autor de El comerciante inglés decidió traducir una obra que el día de su estreno en París conoció un estrepitoso fracaso. ¿Era tal vez su intención contribuir — con la traducción de una obra que a pesar de su mala aceptación consideraba dotada de interés - a la difusión en nuestro país de un género introducido con el fin de renovar la escena española? Algo hace pensar que esta personalidad anónima pertenece a ese primer grupo de traductores que, siguiendo la iniciativa de Aranda, se propuso dar a conocer en España las últimas tendencias de las literaturas extranjeras. El comerciante inglés es una traducción fiel, una copia casi exacta, de Le fabricant de Londres. Esa fidelidad al texto de origen, ese respeto tan escrupuloso de la obra traducida, son precisamente las características esenciales de las traducciones del primer período antes señalado. Llegan los años ochenta y noventa, y las cosas cambian. Se traducen nuevas obras y se hacen segundas versiones de las ya traducidas. Su comparación resulta ilustrativa para explicar la evolución que siguió el género sentimental en España cuando dejó de ser poco menos que un "proyecto de laboratorio" (qué es si no El delincuente honrado), una mera copia de modelos foráneos, y se convirtió en uno más entre los muchos tipos de comedia hispana que aplaudieron los espectadores de finales de siglo.

Le fabricant de Londres", "drame", está escrito en prosa y en cinco actos, divididos respectivamente en 9,13,12, 12 y 6 escenas. La trama, a pesar de su inverosimilitud, está bien trazada, y se resumé en pocas líneas. Un honrado comerciante londinense, Vilson, viudo y con dos hijos, va a casarse con Fanni, hija de Madame Sonbrige y de Lord Falkland, que abandonó a ésta para contraer un matrimonio impuesto. Momentos después de la ceremonia, Vilson recibe la noticia de su irremediable ruina por haber quebrado el banquero que guardaba su capital. Al no poder hacer frente al pago de ciertas letras, sus bienes son embargados y el comerciante, desesperado, decide suicidarse. En un puente sobre el Támesis, lugar elegido para su muerte, encuentra a un desconocido con idénticas intenciones, quien, tras enterarse de la situación de Vilson, piensa que nada mejor para terminar sus días que realizar una generosa donación que permita al fabricante de paños reiniciar su negocio. Alertados por una carta que Vilson dirigió a su esposa antes de abandonar el hogar, llegan al puente los trabajadores de la fábrica,

8. Comedia nueva en prosa El comerciante inglés, en cinco actos, Barcelona, Gibert y Tutó, s. f., 35 pp. Las citas o referencias posteriores serán de esta edición.

9. Fenouillot de Falbaire, Charles-Georges: Le fabricant de Londres, París, Delalain, 1771, $56 \mathrm{pp}$. Todas las referencias corresponderán a esta edición. 
Fanni y su madre. El final feliz es completo al descubrirse que el misterioso benefactor de Vilson es el mismísimo Lord Falkland, que, ya viudo, había vuelto en busca de Madame Sonbrige y su hija y que había decidido quitarse la vida al no encontrarlas y creerlas muertas en un naufragio.

Ni una sola variante en la estructura dramática se observa en El comerciante inglés; la prosa es respetada, así como los cinco actos. Hay una leve variación en el número de escenas: $9,12,11,12$ y 6 en la obra española. Los cambios son debidos a que el anónimo autor considera las escenas 12 y $13 \mathrm{del}$ segundo acto del original como una sola, al igual que las escenas 8 y 9 del acto tercero.

Nada ha cambiado tampoco en lo que se refiere al número y carácter de los personajes, salvo que el "Dramatis Personae" se limita a enumerarlos sin transcribir su condición y su mutua relación, como aparecen en el original. Se ha producido, eso sí, la españolización de algunos nombres: David, el cajero, es en El comerciante Davide, y los hijos de Vilson, Juliette y Henri, Julieta y Enrico respectivamente (Enrique en el "Dramatis Personae"). El resto de los nombres permanecen inalterados, o han sufrido leves variaciones ortográficas (resultado, sin duda, de una adecuación fonética al español) ${ }^{10}$ : Madame Sonbrige $=$ Madama Sombrís, Fanni $=$ Fani, Betzi = Betsi, y James $=$ Yames $^{11}$.

Un aspecto interesante es el cambio de título con respecto a la pieza original. ¿Por qué hacer de un fabricant un comerciante? ¿Por qué "inglés" y no "de Londres"? Pero será tal vez más pertinente responder a estas preguntas al analizar la obra de Valladares.

Por lo demás, el autor español sigue al pie de la letra el texto francés. Las réplicas de los personajes se suceden (como los acontecimientos) en el mismo orden sin alterar palabra. Sólo he detectado dos pequeñas omisiones: la supresión de una fecha, "sept mai 1768", que David escribe en su libro de cuentas $(I, 6)$ - con lo que en el texto español se pierde toda referencia temporal-, y una réplica de Lord Falkland a su criado $(\mathrm{V}, 3)$.

Lo que sí ha disminuido en proporciones considerables son las acotaciones escénicas, abundantísimas (en algunas escenas ocupan más espacio que el propio texto) en Le fabricant. Es posible que el autor español quisiera aligerar su obra evitando tan prolijas descripciones de las muestras de sentimiento y pesar de los personajes o de cada uno de sus movimientos. En todo caso, esa tendencia a reducir las acotaciones es muy habitual en

10. Razones de la misma índole hacen que otros nombres de personas, lugares o términos propiamente ingleses sean transcritos con variantes: Dublin $=$ Dublino, Neucastle $=$ Neucastel, Westminster $=$ Westminstér, scheling $=$ scelino, spleen $=$ esplin .

11. El resto de los personajes son: el propio Vilson, Lord Falkland, William = un ministro, un marchand = un comerciante, Milk, un recaudador, un laquais de Lord Orsey = criado, un laquais de Lord Falkland $=$ criado, un sergent et six records $=$ un sargento y seis soldados (estos últimos no aparecen en el "Dramatis Personae"), y six ouvriers = trabajadores. 
todas las traducciones de obras sentimentales francesas, en especial, en su primera época. El resultado es, como en este caso, una obra de tono menos patético, lo cual no hace sino beneficiar a un género que en ocasiones se excedió en las dosis de lágrimas, desmayos y escenas conmovedoras.

La única adición que aparece en El comediante es la descripción del escenario, de la que, curiosamente y dada la sobreabundancia de otros detalles escénicos, carece la pieza original. Partiendo, sin duda, de datos diseminados a lo largo del texto francés, el autor español describe así la casa del comerciante:

La Scena representa lo interior de una tienda. A la izquierda mesa con escribanía. A la derecha dos mesas chicas, y una pequeña para dos chicos; una chimenea con un relox. Algunas sillas a una parte y otra, y algunas poltronas. El teatro está dispuesto de modo que desde el tablado se ve lo que se hace en la tienda. Dos puertas; la una a la derecha, al primer bastidor, que conduce a la Oficina de paños; y otra a la izquierda al último bastidor que va a las puertas superiores.

El comerciante inglés es, en definitiva, una traducción completamente fiel de Le fabricant de Londres, una copia casi exacta de un texto al que sin duda supera, escrita con corrección y una cierta elegancia de estilo que no todos los autores españoles del género lograron alcanzar.

No podemos decir lo mismo de la versión de Valladares ${ }^{12}$. El texto de Fenouillot de Falbaire está tan alterado y Valladares - fiel a sus métodosha añadido tanto aquí y cortado tanto allá, que se hace difícil aplicarle al Fabricante de paños el calificativo de traducción.

No me detendré en desarrollar ciertos aspectos de esta versión en relación con el original que ya han sido puestos de relieve por el profesor Guinard en un trabajo ${ }^{13}$, al que remito, que pretende analizar la imagen que el público español de los últimos años del siglo XVIII pudo formarse de Inglaterra a través de una serie de obras dramáticas localizadas en aquel país o de tema inglés.

Valladares lo altera todo o casi todo. Pone en octosílabos lo que en francés está en prosa; reduce los cinco actos originales a cuatro; altera el orden de las escenas ( $y$, por tanto, de los acontecimientos); dibuja con trazos muy diferentes el carácter de algunos personajes; cambia nombres o los pone a quien no los tiene; corta, en fin, con bastante generosidad párrafos y hasta réplicas enteras, y añade, eso sí, largas tiradas de versos a las

12. Valladares de Sotomayor, Antonio: Comedia Nueva. El fabricante de paños o el comerciante inglés, puesta en verso en quatro actos, s. 1., s. f., 28 pp. Todas las referencias tendrán como base esta edición.

13. Guinard, P-J.: "Sobre el mito de Inglaterra en el teatro español de fines del XVIII: Una adaptación de Valladares de Sotomayor.", Anales de Literatura Española, Universidad de Alicante, $\mathrm{n}^{\circ} 3,1984$, pp. $283-304$. 
que en modo alguno da pie el texto original.

Pero vayamos por partes. Que los octosílabos sustituyan a la prosa francesa no es sorprendente cuando el verso sigue siendo la forma mayoritaria de expresión. La división en cuatro actos, inusual y bastante extraña, ya es más difícil de explicar, sobre todo cuando ello atenta contra las normas más elementales de la dramática al agrupar en el primer acto la presentación y parte del nudo de la trama (actos I y II del origina) y rompe el equilibrio estructural de la obra francesa. La alteración del orden de algunas escenas no tendría mayor importancia si con ello no se adelantara en cierta medida el desenlace, privando al espectador de la sorpresa final en la última escena ${ }^{14}$. La diferente caracterización de algunos personajes desfigura considerablemente la obra original, pero es el más importante cambio llevado a cabo por Valladares y está hecho de modo coherente, con lo cual la obra española tiene un tono y unos matices muy distintos, perfectamente acordes con la ideología y las características del género sentimental en España. Las adiciones al texto de origen están todas relacionadas con este nuevo aspecto introducido por Valladares; las supresiones, en cambio, parecen bastante caprichosas. En cuanto a los cambios de nombres, lugares o datos, las explicaciones pueden ser diversas.

Paul Guinard ha analizado las posibles causas de estos cambios ${ }^{15}$. Como en El comerciante inglés, se deben, sin duda, a un deseo de asimilación fonética al español (en el caso de Madama Sambrig, Fania y Villianz), aunque lo más frecuente es que los nombres sean traducidos o sustituidos por nombres españoles $($ Milk = Roberto, James = Jayme, Juliette = Isabela, Henri $=$ Enrique, y Lord Falkland pasa a llamarse Lord Baltton ${ }^{16}$ ). A Betsi, los

14. El desenlace de la obra francesa se produce de esta manera: Vilson contempla el Támesis al que va a arrojarse, al tiempo que Lord Falkland se pasea por el puente de Westminster consternado por la noticia que acaban de comunicarle: Fanni y su madre han muerto en un naufragio. Se siente culpable de estas muertes y decide también suicidarse. Se encuentra con Vilson, le detiene cuando éste está a punto de tirarse al río y le obliga a contarle la causa de sus males. El noble escocés decide legarle su fortuna. Fanni y los demás personajes llegan al puente en busca del comerciante, y Lord Falkland descubre entonces que Fanni y su madre no han muerto. Vilson podrá pagar sus deudas con el dinero de su suegro y el noble podrá por fin cumplir la palabra de matrimonio dada a Madame Sonbrige.

El desenlace de la obra española es, de hecho, el mismo, pero la manera de producirse es completamente diferente. Cuando Vilson confiesa la razón que le mueve a quitarse la vida al desconocido con quien se cruza en el puente, éste le reprende duramente; inmediatamente después se identifica como Lord Baltton de Escocia, y el fabricante le informa, emocionado, que Madama Sambrig y su hija, a las que creía muertas, están vivas y en su propia casa. Tiene lugar entonces un cambio de decorado. Voivemos a casa del comerciante. Todos creen ya muerto a Vilson, quien, ante la sorpresa general, aparece acompañado de Lord Baltton. Se produce entonces la clásica escena de reconocimiento entre el noble escocés y Madama Sambrig. Pero Valladares añade una escena más, de la que hablaremos más adelante.

15. Op. cit., pp. 297-300.

16. Sobre el significativo cambio de nombre de este personaje, cf. Guinard: op. cit., p. 299. 
criados, los seis trabajadores de la fábrica y los alguaciles, añade Valladares un escribano que no aparece en el original.

El tema de la obra de Fenouillot de Falbaire y de sus versiones españolas es la descripción de la vida de un comerciante, los riesgos a los que está sometido su oficio y la recompensa final por sus desvelos, en una época en la que la política económica tanto de Francia como de España tendió a potenciar la actividad mercantil. Valladares mantiene inalterado ese tema central, pero dándole un matiz nuevo.

Le fabricant de Londres es una obra fundamentalmente laica, cuya lección podría resumirse en que la condición del comerciante está expuesta a muchos peligros y a los caprichos del azar, aunque siempre la honradez y la virtud lograrán su recompensa. La obra de Valladares es esencialmente religiosa en este aspecto: es una lección sobre la virtud cristiana de la resignación. Ante la adversidad, el cristiano debe resignarse y aceptar la voluntad de Dios, sin dejar por ello de confiar en Él y de esperar la feliz solución de sus problemas.

En consecuencia, Valladares hace que sus personajes reaccionen ante la ruina del comerciante de manera muy distinta a como lo hacen los personajes del drama francés. En un interesante diálogo entre Vilson y su esposa, Valladares añade al original, entre otras, estas frases de Fania:

Los bienes,

las riquezas de esta vida, sienten perderlas aquellas almas débiles que vician su noble ser, con tener por su ídolo a la codicia. Pero quien sabe que todo lo de este mundo es ceniza, tierra, polvo, humo, nada, al ver su hacienda perdida, se consuela con decir:

Dios la dio y me la quita. Haz tú lo mismo, y verás cómo tu pena se alivia. (...)

Dios, que cuida de las hormigas, dándolas para vivir aquello que necesitan, ¿no ha de cuidar de su imagen y semejanza? Bendita su misericordia sea, que nunca ahoga, aunque aflija. (III) 
Isabela le da a su padre el collar que Fania le regaló para que pueda pagar con él a los obreros, diciendo:

(Tomadlo;

pero no lloréis, por Dios.

Puede que otra vez seamos

ricos); Dios, que da los bienes,

tambien nos los quita quando

quiere, y con su voluntad

es preciso resignarnos. (II) ${ }^{17}$

Cuando Roberto comunica a su patrón la quiebra del banquero Sudmer, le da ánimo con estas palabras:

Confiad en la Providencia, que a todo dará remedio,

Señor. (I)

Igualmente señala Valladares que la generosidad de Isabela con los pobres (ha pedido un "realito" a Roberto para dárselo como limosna a un pobre), no es sólo humanitarismo, como podría pensarse del gesto de Juliette, sino una virtud y un deber cristiano que el Cielo se encargará de recompensar:

\author{
El Cielo, \\ dice mi papá, que da \\ ciento por uno; y yo quiero \\ sembrar mucho entre los pobres, \\ que así se halla un fruto cierto. (I)
}

Dentro de este contexto moral y religioso debemos considerar otro detalle original de El fabricante de paños: el rechazo y condena tajantes del suicidio. Cuando, en el puente sobre el Támesis, Vilson anuncia a Lord Baltton su intención de quitarse la vida, éste - que a pesar de la desesperación por la que cree muerte segura de Fania y su madre, no ha pensado, como el Lord Falkland de la obra francesa, en suicidarse- le reprende duramente con un severo discurso contra el suicidio, recordándole las leyes divinas y las humanas. El texto es largo, pero merece ser citado:

\footnotetext{
Amigo, yo he contemplado, mientras he estado suspenso, que no procedes como hombre, si no qual bruto; estás ciego
}

17. Las palabras entre paréntesis se encuentran en el original francés. 
de la desesperación, que quita el conocimiento. Aun quando no nos prohibieran las Leyes, y los preceptos Divinos, ser homicidas, (qué horror!) de nosotros mesmos, la humanidad sola inspira el amor con que debemos nuestra vida conservar. ¿Y qué causa es la que advierto en ti, para quebrantar este Santo Mandamiento, las Leyes, la humanidad, y hacerte sordo a los tiernos gritos que naturaleza te da, tu error conociendo? La pérdida de unos bienes. $Y$ discurres que son éstos a ti superiores? ¡Ah! ¿Qué engaño tan manifiesto! El oro es tierra. ¿Y el hombre? El hombre no es nada menos que imagen de su Criador; puede gozarle sabiendo servirle, iy por una cosa tan despreciable, al Eterno mal te abandonas! Tú tienes muger virtuosa, hijos vellos, y porque Dios te ha quitado lo que te dio, quitas a ellos un padre, un esposo, un dulce asilo en su desconsuelo, un apoyo en sus miserias, y en sus males el remedio. ¡Hombre bárbaro, el que piensa como tú! Qué, ¿estás creyendo que la desesperación es valor? Pues no: es efecto de un alma débil, baxeza del ánimo, y verdadero carácter del que es cobarde. (IV)

El teatro sentimental es esencialmente maniqueo en la caracterización de sus personajes. Pretende transmitir el mensaje de que el hombre debe ser virtuoso (en el amplio mensaje que esta palabra tenía en el siglo XVIII), 
porque sólo así logrará su felicidad, la de sus semejantes y la del conjunto de la sociedad. Por ello, el esquema básico al que recurre es la presentación de la virtud perseguida y finalmente siempre triunfante.El maniqueísmo de los caracteres se presenta entonces cono una necesidad intrínseca. Nada mejor, pues, que personajes buenos y personajes malos. Y para que la línea que los separa sea neta y la lección moral que transmite el drama no ofrezca lugar a equívocos, los autores no dudan en cargar las tintas para poner de relieve la excesiva bondad de unos y la extrema maldad de los otros.

Buen ejemplo de ello es la versión de Valladares. La división de caracteres existe, cierto es, en Le fabricant y se mantiene en el mismo grado en El comerciante. Pero don Antonio considera que un poco de exageración no vendría mal, siempre en aras de la mayor moralización del texto.

William es, en Le fabricant, amigo del comerciante y actúa como ministro en la ceremonia de su boda ${ }^{18}$. Al conocer la ruina de Vilson, desoye las peticiones de Fanni y su madre para que ayude al comerciante, y presenta una letra de cambio que espera cobrar inmediatamente, so pretexto de que el dinero no es suyo, sino que le fue confiado por otras personas. Fanni le paga con sus pendientes de diamantes y el Ministre se marcha recibiendo la crítica generalizada por su indigno comportamiento.

Todo queda ahí. Pero Valladares añade mucho más a la figura del falso amigo. Empieza por presentar a un Villianz (Vilian o Viliam, en otras páginas del texto) aparentemente más virtuoso que su homónimo francés: "Qué bella alma tiene!", dice de él Vilson (I), y Fania: "Él junta gruesas limosnas / sólo para mantenerlos (a los pobres)." (I). El ensalzamiento de su virtud aparente provoca un contraste más fuerte con su actuación indigna al negarse a ayudar a su amigo. Pero, por si los hechos no fueran suficientes por sí mismos, Valladares se cuida de añadir una serie de apartes en los que el hipócrita desvela su auténtico carácter. Selecciono algunos:

Yo así engaño

a los simples, y acreciento

mi oro, porque él es mi encanto. (II)

¿Tres mil libras esterlinas

ha perdido (¡estoy temblando!)

en esta quiebra Vilson?

Pues él se arruinó; ¡si acaso

18. De hecho, su nombre de pila sólo aparece en el "Dramatis Personae"; durante toda la obra, los demás personajes se refieren a él como "Ministre". No hará falta aclarar que los personajes de la obra francesa profesan la religión protestante. El enlace de Vilson y Fanni se celebra en un temple, Juliette recibe la felicitiación del Ministre por haber aprendido un capítulo entero de la Biblia, y Henri es alentado a imitar a su hermana para llegar a ser un "petit Ministre". Todo ello permanece inalterado en El comerciante; pero en El fabricante de paños toda referencia al protestantismo ha desaparecido. Villianz es, en la versión de Valladares, el padrino de boda. 
la letra que en mi poder tengo contra él (golpe amargo)

no me pagará! ¡El canalla

de este modo ha asesinado

mi corazon! ¡Oh dinero

de mi alma! (II)

Ya estoy rabiando

por salir de aquí; pues casa

donde no hay que agarrar algo,

me apesta. (II)

La virtud siempre triunfa, y la maldad es castigada sistemáticamente en el género sentimental. Por ello, Valladares necesita añadir una escena final (a la que antes aludí) a una obra ya conclusa. En medio del regocijo general de la última escena, aparece Villianz reclamando una guinea que le falta para saldar la deuda de Vilson tras las venta de los pendientes de Fania. La suerte quiere que Villianz sea un antiguo conocido de Lord Baltton, quien ya le juzgó y condenó una vez por robar a los pobres. El hipócrita y malvado Villianz será condenado a prisión y la lección habrá quedado completa.

También las acotaciones del original aparecen considerablemente reducidas en El fabricante. El resultado es el mismo que en el caso de El comerciante: una obra de gestos menos patéticos apoyada en un texto ya de por sí bastante conmovedor. Valladares, por ejemplo, no ha sabido sacar partido a la presencia de los hijos del comerciante ${ }^{19}$. Los niños son siempre un estupendo recurso que acentúa el toque de sentimentalismo de muchas comedias del género ${ }^{20}$. Al reducir notablemente su papel, ha privado al espectador de escenas tan conmovedoras como la patética despedida de Vilson a sus hijos cuando decide suicidarse, o la amargura de Falkland al coger en brazos a Juliette y recordar a la hija que abandonó.

Queda aún por analizar la cuestión del título. Paul Guinard ha dado una clara explicación para la obra de Valladares, y nada mejor que remitirse a él:

El original se titula simplemente Le fabricant de Londres. Valladares duplica este sintagma nominal con otro propuesto a modo de alternativa equivalente o explicación, extendiendo así los dos conceptos incluidos en el título francés; reproduce el de "fabricante", pero le parece necesario explicitarlo con el de "comerciante". La razón tal vez será que si en francés "fabricant"es unívoco, en el uso español de la época "fabricante"es ambiguo, ya que puede nombrar tanto al que

19. Por problemas de reparto, sugiere Guinard, op. cit., p. 300.

20. Véase, por ejemplo, el importante papel que juegan en Misantropía y arrepentimiento o Las victimas del amor, Ana y Sindham. 


\begin{abstract}
"toma a su cuenta una fábrica, cuida de ella y mantiene a los oficiales necesarios para la obra" como a "los oficiales que los (lanas y paños) trabajan en la fábrica misma en que se hacen". Esta ambiguiedad desaparece con la aclaración de "comerciante", que se aplica a un hombre dedicado a los negocios y dispone del capital necesario para ello. Se observará además que Valladares sustituye "de Londres" por "inglés" como para dar a su personaje un carácter representativo de la nación inglesa (con las connotaciones de lucrativa actividad que esto supone), acaso más explícito para el público que la mera referencia a una ciudad. ${ }^{21}$
\end{abstract}

En el caso de la versión anónima, la elección del término "comerciante” elimina la ambigüedad del "fabricante". De hecho, los trabajadores de la fábrica de Vilson, denominados siempre así, "trabajadores", son designados en la primera escena como "fabricantes", señal inequívoca de que son ellos quienes realizan los tejidos y el comerciante es sólo el dueño del negocio.

El teatro sentimental estuvo en los escenarios españoles durante más de medio siglo, y conoció etapas bien diferentes, desde los inicios, ligados estrechamente a la Ilustración, hasta la decadencia, marcada por la pérdida de una buena parte de su ideología y el aumento incontrolado de las dosis de sentimentalismo. Empezó siendo un género importado, y acabó hermanado con otras formas de comedia típicamente hispanas. En ese largo camino, las motivaciones de sus autores, la calidad de la producción y la actitud del público fueron muy diversas.

Por lo que se refiere a las obras traducidas del francés, todo ello queda bien ejemplificado con las dos versiones españolas aquí reseñadas. El anónimo autor de El comerciante inglés hizo lo que pretendía: una traducción fiel que sirviese (es una hipótesis, pero creo que bastante fundada) para difundir en España un género todavía no muy conocido. Y lo hizo con criterios estéticos estrictos que dieron como resultado una obra de calidad, equilibrada en la estructura y moderada en el tono.

Valladares, seis años más tarde, se propuso otra cosa: adaptar un texto extranjero de un género que ya empezaba a ser popular a los gustos dramáticos de un público educado en una tradición reñida con los proyectos reformadores. Por eso, retomó un texto ya traducido cuyo tema continuaba

21. Op. cit., p. 249. Sobre la denominación de los trabajos manuales en la España de finales del XVIII, véase el interesante artículo del propio Guinard: "Remarques sur la dénomination des travailleurs manuels dans le Discurso sobre el fomento de la industria popular et le Discurso sobre la educación popular de Campomanes", París, Ibérica, IV, 1983, pp. 154-175.

Es interesante destacar que el registro de El comerciante en este campo semántico es mucho más reducido que el empleado por Fenouillot de Falbaire y Valladares. El primero utiliza los términos "fabricant", "négociant", "ouvriers", "atelier", "magasin", "boutique" y "manufacture". En El fabricante de paños aparecen "fabricante", "comerciante", "mercader", "oficiales", "telares", "tienda" y "almacén". Por fin, en El comerciante inglés encontramos "comerciante", "trabajadores" (una sola vez "fabricantes"), "oficina" y "tienda". 
siendo de plena actualidad y que llevaba toda la carga ideológica que el género seguía encerrando en estos años. Pero lo hizo con criterios estéticos muy diferentes. Valladares de Sotomayor, refundidor de Lope, autor de comedias heroicas y de magia, de tragedias y de sainetes, es un hombre de teatro; conoce los gustos de los espectadores, y en función de ellos escribe. El octosílabo asonantado, la polimetría, las escenas de canto y baile, las acciones dobles, los seudo-graciosos, la complicación novelesca de la trama, la irregularidad de la estructura dramática, la escenografía y los decorados sorprendentes de su teatro sentimental son una concesión a ese público.

De ahí que Valladares se muestre siempre tan irrespetuoso con los originales que traduce, porque sus versiones no serán, como las primeras traducciones de piezas sentimentales francesas, espectáculo reservado a la minoría culta y con ideas reformadoras de los teatros de salón o de los Reales Sitios, sino teatro popular.

De ahí, en fin, que El fabricante de paños resulte una obra más española que El comerciante inglés, y no porque las libras esterlinas hayan sido sustituidas por reales o los personajes no sean protestantes sino católicos. La clave no está ahí. Es más española, sencillamente, porque se parece más al teatro que los espectadores madrileños veían en 1784 y porque ha incorporado elementos de ese teatro.

El comerciante inglés y El fabricante de paños representan dos etapas en la historia del teatro sentimental francés en España; muestran cómo ha pasado de ser traducido a ser adaptado. Este proceso va en detrimento de la calidad del producto, es cierto, pero explica el fenómeno de recepción de un género extranjero hasta su total integración en la dramaturgia de otro país. 